\title{
Role of equilibration before rapid freezing of mouse embryos
}

\author{
A. Széll and J. N. Shelton \\ Department of Immunology, The John Curtin School of Medical Research, Australian National \\ University, P.O. Box 334, Canberra 2601, A.C.T., Australia
}

\begin{abstract}
Summary. The time requirements for permeation by glycerol and dehydration by sucrose before rapid freezing of Day-3 mouse embryos by direct transfer to $-180^{\circ} \mathrm{C}$ were studied. When the embryos were equilibrated in $2 \cdot 0,3 \cdot 0$, or $4.0 \mathrm{M}$-glycerol $+0.25 \mathrm{M}$ sucrose for 2.5 to $40 \mathrm{~min}$, the post-thaw viability increased $(P<0.001)$ with the length of equilibration period at $4^{\circ} \mathrm{C}$. At $20^{\circ} \mathrm{C}$ the volume of embryos increased with the duration of equilibration up to $20 \mathrm{~min}(P<0.001)$, but the post-thaw viability was not affected.

The effect of equilibration in glycerol-sucrose was determined at $20^{\circ} \mathrm{C}$ for embryos which were previously permeated by glycerol, dehydrated by sucrose or left in PBS + $5 \%$ FCS. The survival of previously permeated embryos was not affected by equilibration for 1-16 min in glycerol-sucrose. The maximum survival rate was attained after shorter equilibration in glycerol-sucrose for embryos without pretreatment ( $4 \mathrm{~min}$ ) than for those previously dehydrated $(8 \mathrm{~min})$.

It is concluded that increases in the intracellular glycerol level are beneficial for the viability of rapidly frozen mouse embryos and previous or concommitant exposure to sucrose unfavourably affects glycerol permeation.
\end{abstract}

\section{Introduction}

The two main causes of cellular death during freezing and thawing are intracellular ice formation and solution effects (Mazur, 1970). Intracellular ice formation occurs when the cells are not sufficiently dehydrated at a given subzero temperature. Dehydration by slow freezing rates (Leibo $e t$ al., 1978; Whittingham et al., 1979) or by exposure to a nonpermeable solute (Nguyen et al., 1983) protects the cells against intracellular ice formation.

The other main form of cellular death is caused by alterations in the cytoplasm and the surrounding medium. As the liquid water content of these compartments is transformed into ice, the salt concentration increases. These changes were referred to as solution effects by Lovelock (1953) who found that the cells died when the salt concentration in the suspending medium reached a critical level during freezing. As a result of damage caused by solution effects, mammalian cells irrespective of the degree of dehydration do not survive freezing below about $-20^{\circ} \mathrm{C}$ unless the freezing medium contains cryoprotectants. The cryoprotective effect of glycerol has been attributed to its ability to reduce the salt concentration in the unfrozen fraction of partly frozen solutions (Lovelock, 1953; Rall et al., 1978).

The role of intracellular glycerol in the cryoprotection of embryos can be studied under conditions which provide various degrees of permeation before freezing. The need for glycerol permeation before freezing was demonstrated for mouse unfertilized eggs and 1-cell embryos (Jackowski \& Leibo, 1976), but increasing the duration or temperature of equilibrium had no effect on the viability of frozen-thawed 8-cell embryos (Leibo \& Mazur, 1974). These differences can be explained with the increases in the permeability of mouse eggs caused at fertilization (3-fold) 
and after further development to 8-cell stage (10-fold) (Mazur et al., 1976; Jackowski et al., 1980). Solution effects become less severe with higher freezing rates (Mazur, 1980), suggesting that glycerol may become less important for embryos frozen rapidly. However, Széll \& Shelton (1986) showed that embryos dehydrated by sucrose and frozen at extremely high rates required higher extracellular concentrations of glycerol for survival than did those frozen by traditional slow rate freezing (Leibo \& Mazur, 1974). The aim of the present work was to examine the role of intracellular glycerol and the time requirements for dehydration by sucrose before rapid freezing of 8- to 16-cell mouse embryos.

\section{Materials and Methods}

Source of embryos. WEHI outbred mice (6-12 weeks of age) were superovulated by intraperitoneal injections of 5 i.u. PMSG and 2 i.u. hCG given $46 \mathrm{~h}$ apart. The females were individually paired with males at the time of the second injection and checked for vaginal plugs the next morning. Embryos were obtained 66-70 $\mathrm{h}$ after the hCG injection by flushing the reproductive tracts with Dulbecco's phosphate-buffered saline supplemented with $5 \%$ fetal calf serum (PBS $+5 \%$ FCS). Morphologically normal 8- to 16-cell embryos were collected and washed in several changes of medium.

Osmotic studies. The osmotic behaviour of the embryos was studied at $20^{\circ} \mathrm{C}$ in glycerol-sucrose solutions $(2 \cdot 0,3.0$ or $4.0 \mathrm{M}$-glycerol $+0.25 \mathrm{M}$-sucrose) by taking photographs after $2 \cdot 5,5,10,20$ and $40 \mathrm{~min}$ exposure (Exp. 1). Experiment 1 had 5 replications. Through a larger pool of identical medium, the embryos were pipetted into a drop of glycerol-sucrose solution which was covered by oil to prevent evaporation. The volume of the embryos was determined from their cross-sectional area, assuming a spherical shape, and was expressed as a percentage of the isotonic volume.

Embryo freezing. In Exps 2 and 3 the embryos were equilibrated before freezing for 2.5, 5, 10, 20 or $40 \mathrm{~min}$ in glycerol-sucrose solution $\left(2 \cdot 0,3 \cdot 0\right.$, or $4 \cdot 0 \mathrm{M}$-glycerol $+0 \cdot 25 \mathrm{M}$-sucrose) at $4^{\circ} \mathrm{C}$ (Exp. 2$)$ or $20^{\circ} \mathrm{C}$ (Exp. 3). Experiments 2 and 3 had 3 and 5 replications respectively in each of which 20 embryos were frozen per experimental group.

Experiments 4 and 5 were designed to assess the time requirements for permeation by glycerol independently from those for dehydration by sucrose. In Exp. 4 the embryos were first dehydrated in $0.25 \mathrm{M}$-sucrose at $20^{\circ} \mathrm{C}(10 \mathrm{~min})$ and then placed into $4.0 \mathrm{M}$-glycerol $+0.25 \mathrm{M}$-sucrose at $4^{\circ} \mathrm{C}$ for $2 \cdot 5,5,10,20$ or $40 \mathrm{~min}$ before freezing. Experiment 5 was performed at $20^{\circ} \mathrm{C}$; the embryos were dehydrated by $0.25 \mathrm{M}$-sucrose ( $10 \mathrm{~min}$ ) or equilibrated with $4.0 \mathrm{M}$-glycerol $(10 \mathrm{~min})$ or left in PBS + $5 \%$ FCS before being exposed to $4.0 \mathrm{M}$-glycerol $+0.25 \mathrm{M}$-sucrose for $1,2,4,8$ or $16 \mathrm{~min}$ and then frozen. Experiments 4 and 5 had 3 replications in each of which 20 embryos were frozen per group.

The embryos were frozen in $0.5 \mathrm{ml}$ plastic straws as described in detail by Széll \& Shelton (1986). The straw contained $40 \mu \mathrm{l}$ glycerol-sucrose solution (freezing medium) separated by an air bubble from $440 \mu 11.0 \mathrm{M}$-sucrose solution (diluent). Groups of 20 embryos in about $1 \mu \mathrm{l}$ medium were placed into the freezing medium fraction of the straws. The straws were frozen by placing them into the vapour of liquid nitrogen (about $-180^{\circ} \mathrm{C}$ ) and $3-5 \mathrm{~min}$ later into liquid nitrogen itself. After storage for 5 days or longer in liquid nitrogen, the straws were thawed in a $35^{\circ} \mathrm{C}$ water bath. The two fractions were mixed (Leibo et al., 1982; Renard et al., 1982) and the straws were held for $10 \mathrm{~min}$ at $20^{\circ} \mathrm{C}$ (Széll \& Shelton, 1986) to allow glycerol removal from the embryos which were then washed in PBS + 5\% FCS and cultured in Whitten's medium for 2 days.

Statistical analysis. The results were evaluated by analysis of variance. Experiment 1 was of splitplot design in which measurments on the same embryo at different times constituted the subplots. In Exps 2, 3, 4 and 5 the experimental unit was a group of 20 embryos. The numbers of frozenthawed embryos developing to blastocysts in culture were expressed as the proportions 
Table 1. Mean volume of Day-3 mouse embryos $(n=5)$ expressed as a percentage of their isotonic volume after exposure to $2 \cdot 0,3.0$ or $4.0 \mathrm{M}$-glycerol $+0.25 \mathrm{M}$-sucrose for 2.5 to $40 \mathrm{~min}$ at $20^{\circ} \mathrm{C}$ (Exp. 1)

\begin{tabular}{|c|c|c|c|c|c|c|}
\hline \multirow{2}{*}{$\begin{array}{l}\text { Glycerol } \\
\text { conc. (M) }\end{array}$} & \multicolumn{5}{|c|}{ Duration of exposure (min) } & \multirow[b]{2}{*}{ Mean } \\
\hline & 2.5 & 5 & 10 & 20 & 40 & \\
\hline $\begin{array}{l}2.0 \\
3.0 \\
4.0\end{array}$ & $\begin{array}{l}48 \\
53 \\
53\end{array}$ & $\begin{array}{l}56 \\
61 \\
61\end{array}$ & $\begin{array}{l}57 \\
69 \\
66\end{array}$ & $\begin{array}{l}59 \\
71 \\
70\end{array}$ & $\begin{array}{l}61 \\
72 \\
72\end{array}$ & $\begin{array}{l}56 \\
65 \\
64\end{array}$ \\
\hline Mean & $51^{a}$ & $59^{\mathrm{b}}$ & $64^{b c}$ & $67^{\circ}$ & $68^{\mathrm{c}}$ & 62 \\
\hline
\end{tabular}

Means with different superscripts $(a, b, c)$ are significantly $(P<0.001)$ different.

Table 2. The effect of duration of equilibration in $2.0,3.0$ or $4.0 \mathrm{M}$-glycerol $+0.25 \mathrm{M}$-sucrose at $4^{\circ} \mathrm{C}$ and at $20^{\circ} \mathrm{C}$ on the percentage of embryos surviving after freezing and thawing (Exps 2 and 3)

\begin{tabular}{lccccccccc}
\hline & & & \multicolumn{6}{c}{ Equilibration time (min) } \\
\cline { 5 - 8 } Exp. & Temp. & $n$ & $\begin{array}{c}\text { Glycerol } \\
\text { conc. (M) }\end{array}$ & $2 \cdot 5$ & 5 & 10 & 20 & 40 & Mean \\
\hline 2 & $4^{\circ} \mathrm{C}$ & 60 & $2 \cdot 0$ & 0 & 12 & 8 & 17 & 25 & 12 \\
& & & $3 \cdot 0$ & 13 & 40 & 48 & 68 & 66 & 47 \\
& & $4 \cdot 0$ & 2 & 17 & 50 & 77 & 78 & 45 \\
& & & Mean & $5^{\text {a }}$ & $23^{\mathrm{b}}$ & $36^{\mathrm{b}}$ & $54^{\mathrm{c}}$ & $57^{\mathrm{c}}$ & 35 \\
\hline 3 & $20^{\circ} \mathrm{C}$ & \multirow{2}{*}{100} & $2 \cdot 0$ & 22 & 20 & 22 & 22 & 18 & 21 \\
& & $3 \cdot 0$ & 65 & 64 & 72 & 58 & 63 & 64 \\
& & $4 \cdot 0$ & 65 & 63 & 74 & 66 & 45 & 63 \\
& & & Mean & 51 & 49 & 56 & 49 & 42 & 49 \\
\hline
\end{tabular}

Means with different superscripts $(\mathrm{a}, \mathrm{b}, \mathrm{c})$ are significantly $(P<0.01)$ different.

of those frozen and the responses were transformed into angles for analysis. The significance of differences amongst treatment means was established by the method of orthogonal comparisons.

\section{Results}

In glycerol-sucrose solutions the regression of the volume of embryos on the duration of equilibration contained linear and quadratic compartments $(P<0.001)$. The embryos expanded as the duration of exposure increased from 2.5 to $20 \mathrm{~min}(P<0.001)$, but there was no further change afterwards $(P>0.4)$ (Exp. 1, Table 1). The glycerol concentration did not affect the response $(P>0 \cdot 1)$ and there was no interaction between the two factors $(\mathrm{F}<1)$.

In Exps 2 and 3 (Table 2) the embryos were equilibrated for $2.5-40 \mathrm{~min}$ before freezing. At $4^{\circ} \mathrm{C}$ (Exp. 2) the viability of frozen-thawed embryos increased linearly $(P<0.001)$ as a function of equilibration period. At $20^{\circ} \mathrm{C}$ (Exp. 3), although the highest survival was obtained after $10 \mathrm{~min}$, the effect of equilibration period was not significant $(P>0 \cdot 1)$. In both experiments the regression of response on glycerol concentration contained linear and quadratic components $(P<0.001)$. The post-thaw survival was lower in 2.0 than in 3.0 or $4.0 \mathrm{M}$-glycerol $(P<0.001)$, but there was no difference between the last two concentrations. There was no interaction between the concentration of glycerol and the duration of equilibration at either temperature $(P>0.05)$.

In Exp. 4, in which the embryos were equilibrated with $4.0 \mathrm{M}$-glycerol $+0.25 \mathrm{M}$-sucrose at $4^{\circ} \mathrm{C}$ after dehydration by $0.25 \mathrm{M}$-sucrose, the regression of viability on the duration of equilibration was 
Table 3. Percentages of developing frozen-thawed mouse embryos $(n=60)$ as a function of duration of equilibration in glycerol-sucrose at $20^{\circ} \mathrm{C}$ after dehydration by sucrose, permeation by glycerol or without pretreatment (Exp. 5)

\begin{tabular}{lcccccc}
\hline & \multicolumn{5}{c}{ Duration of equilibration (min) } \\
\cline { 2 - 6 } Pretreatment & 1 & 2 & 4 & 8 & 16 & Mean \\
\hline Dehydration & $0^{\mathrm{a}}$ & $22^{\mathrm{b}}$ & $48^{\mathrm{c}}$ & $80^{\mathrm{d}}$ & $50^{\mathrm{c}}$ & 40 \\
Permeation & 78 & 77 & $93^{\mathrm{a}}$ & 82 & 62 & 78 \\
No pretreatment & $13^{\mathrm{a}}$ & $38^{\mathrm{b}}$ & $73^{\mathrm{c}}$ & $75^{\mathrm{c}}$ & $75^{\mathrm{c}}$ & 55 \\
\hline
\end{tabular}

Means within the same row with different superscripts $(a, b, c, d)$ are significantly $(P<0.001)$ different.

linear $(P<0 \cdot 001)$. The percentage of survival after $2 \cdot 5,5,10,20$ and 40 min equilibration was 2,8 , 47,72 and $87 \%$ respectively.

In Exp. 5 (Table 3) the mean survival rate for embryos previously dehydrated with sucrose, permeated with glycerol or without pretreatment was 40,78 and $55 \%$ respectively. The differences between the main effects of any two pretreatments were significant $(P<0.001)$. The duration of equilibration in glycerol-sucrose did not affect the survival of previously permeated embryos $(P>0 \cdot 1)$, but had a significant $(P<0.001)$ effect on the other two groups. The maximum viability was attained earlier $(4 \mathrm{~min})$ for embryos without pretreatment than for those previously dehydrated $(8 \mathrm{~min})$. In the latter group the viability declined at $16 \mathrm{~min}$ of equilibration.

\section{Discussion}

Experiment 1 demonstrated that the volume changes of mouse embryos in glycerol-sucrose solutions follow a pattern similar to that in glycerol solutions (Jackowski et al., 1980) and are characterized by an initial shrinkage and a subsequent gradual expansion. The theoretical basis of this pattern was explained by Schneider \& Mazur (1984). The cells initially lose water and shrink to compensate the high extracellular osmolarity caused by glycerol and sucrose. This relatively fast shrinkage is followed by a more gradual increase in volume as glycerol enters and water re-enters the cells. The equilibration is complete when no further volume changes occur. This can be attained upon reaching the isotonic or a smaller volume. When the embryos are exposed to glycerol-sucrose solutions, only the glycerol will permeate the cells; the extra osmolarity created by sucrose causes dehydration which reduces the occurrence of intracellular ice formation. The occurrence of glycerol permeation in glycerol-sucrose solutions was demonstrated by the re-expansion of embryos. In the present experiments sucrose was also used for cryoprotectant dilution. Relevant aspects of this application have been discussed by Leibo $(1983,1984)$ and Széll \& Shelton (1986).

At $20^{\circ} \mathrm{C}$ the volume and therefore the intracellular glycerol content of embryos exposed to glycerol-sucrose increased with the duration of exposure up to $20 \mathrm{~min}$. However, improvement in the viability of frozen-thawed embryos was evident with equilibration at this temperature only up to about $2.5 \mathrm{~min}$. This period was extended to $20 \mathrm{~min}$ when the rate of glycerol permeation was reduced by decreasing the temperature to $4^{\circ} \mathrm{C}$. The results demonstrated that the survival of rapidly frozen embryos is dependent on the temperature and duration of equilibration. Subsequent experiments, which were designed to study the time dependency in the effects of glycerol and of sucrose independently, showed that the effect of equilibration period was due to glycerol permeation. The viability of already dehydrated embryos also improved with the time spent in glycerol-sucrose, but this factor caused no improvement following permeation by glycerol. The latter result also indicates that, in contrast to glycerol permeation, the required degree of dehydration is attained almost 
instantaneously. The survival rate was higher if the embryos were permeated with glycerol before placing them into glycerol-sucrose. The present results suggest that previous or concomitant exposure to sucrose unfavourably affects the glycerol permeation. Osmotic studies are in progress to investigate this effect further.

Our results demonstrate that increases in the intracellular glycerol level are beneficial for the survival of rapidly frozen embryos, but complete equilibration is not necessary. Therefore the optimal concentration is higher for extracellular than for intracellular glycerol. The mechanism of cryoprotection during rapid freezing, however, cannot be explained by protection against solution effects, since despite the much shorter exposure to such effects higher extra- and intra-cellular glycerol levels are required to protect the embryos compared to controlled (slow) rate freezing.

We thank Ms Heather McDonagh and Ms Klára Széll for excellent technical assistance.

\section{References}

Jackowski, S.C. \& Leibo, S.P. (1976) Response of fertilized mouse ova to freezing and thawing as a function of permeation by glycerol. Cryobiology 13, 646, Abstr.

Jackowski, S., Leibo, S.P. \& Mazur, P. (1980) Glycerol permeabilities of fertilized and unfertilized mouse ova. J. exp. Zool. 212, 329-341.

Leibo, S.P. (1983) A one-step in situ dilution method for frozen-thawed bovine embryos. Cryo-Letters 4, $387-400$.

Leibo, S.P. (1984) A one-step method for direct nonsurgical transfer of frozen-thawed bovine embryos. Theriogenology 21, 767-790.

Leibo, S.P. \& Mazur, P. (1974) The role of glycerol and dimethyl sulfoxide in protecting mouse embryos against freezing damage. J. Cell Biol. 63, 189, Abstr.

Leibo, S.P., McGrath, J.J. \& Cravalho, E.G. (1978) Microscopic observation of intracellular ice formation in unfertilized mouse ova as a function of cooling rate. Cryobiology 15, 257-271.

Leibo, S.P., West, A.W., III \& Perry, B. (1982) A one-step method for direct nonsurgical transfer of frozen-thawed bovine embryos. II. Applied studies. Cryobiology 19, 674, Abstr.

Lovelock, J.E. (1953) The mechanism of the protective action of glycerol against haemolysis by freezing and thawing. Biochim. Biophys. Acta 11, 28-36.

Mazur, P. (1970) Cryobiology: the freezing of biological systems. Science, N.Y. 168, 939-949.

Mazur, P. (1980) Fundamental aspects of the freezing of cells, with emphasis on mammalian ova and embryos. Proc. 9th Int. Congr. Anim. Reprod. \& A.I., Madrid I, 99-114.
Mazur, P., Rigopoulos, N., Jackowski, S.C. \& Leibo, S.P. (1976) Preliminary estimates of the permeability of mouse ova and early embryos to glycerol. Biophys. $J$. 16, 232a, Abstr.

Nguyen, B.X., Renard, J.P. \& Garnier, V. (1983) Rapid freezing and thawing of 2-cell-stage rabbit embryos after partial dehydration at room temperature. Cryobiology 20, 742, Abstr.

Rall, W.F., Mazur, P. \& Souzu, H. (1978) Physicalchemical basis of the protection of slowly frozen human erythrocytes by glycerol. Biophys. J. 23, 101-120.

Renard, J.-P., Heyman, Y. \& Ozil. J.-P. (1982) Congélation de l'embryon bovin: une nouvelle méthode de décongélation pour la transfert cervical d'embryons conditionnés une seule fois en paillettes. Annls Méd. Vét. 126, 23-32.

Schneider, U. \& Mazur, P. (1984) Osmotic consequences of cryoprotectant permeability and its relation to survival of frozen-thawed embryos. Theriogenology 21, 68-79.

Széll, A. \& Shelton, J.N. (1986) Sucrose dilution of glycerol from mouse embryos frozen rapidly in liquid nitrogen vapour. J. Reprod. Fert. 76, 401-408.

Whittingham, D.G., Wood, M., Farrant, J., Lee, H. \& Halsey, J.A. (1979) Survival of frozen mouse embryos after rapid thawing from $-196^{\circ} \mathrm{C} . J$. Reprod. Fert. 56, 11-21

Received 21 April 1986 